\title{
Radiomics for Prediction of Radiation-induced Lung Injury After Robotic Stereotactic Body Radiotherapy of Lung Cancer: Results From Two Independent Institutions
}

\section{Khaled Bousabarah}

Universität zu Köln Medizinische Fakultät: Universitat zu Koln Medizinische Fakultat

\section{Oliver Blanck}

University Hospital Schleswig-Holstein - Campus Kiel: Universitatsklinikum Schleswig-Holstein

\section{Susanne Temming}

Universität zu Köln Medizinische Fakultät: Universitat zu Koln Medizinische Fakultat

Maria-Lisa Wilhelm

Rostock University Medical Center: Universitatsmedizin Rostock

\section{Mauritius Hoevels}

Universität zu Köln Medizinische Fakultät: Universitat zu Koln Medizinische Fakultat

\section{Wolfgang W. Baus}

Universität zu Köln Medizinische Fakultät: Universitat zu Koln Medizinische Fakultat

\section{Daniel Ruess}

Universität zu Köln Medizinische Fakultät: Universitat zu Koln Medizinische Fakultat

\section{Veerle Visser-Vandewalle}

Universität zu Köln Medizinische Fakultät: Universitat zu Koln Medizinische Fakultat

\section{Maximilian I. Ruge}

Universität zu Köln Medizinische Fakultät: Universitat zu Koln Medizinische Fakultat

\section{Harald Treuer}

Universität zu Köln Medizinische Fakultät: Universitat zu Koln Medizinische Fakultat

Martin Kocher ( $\square$ martin.kocher@uk-koeln.de)

Department of Stereotactic and Functional Neurosurgery, University Hospital of Cologne, Cologne, Germany https://orcid.org/0000-0002-5674-9227

\section{Research}

Keywords: non-small cell lung cancer (NSCLC), radiomics model, predictive clinical and dosimetric parameters

Posted Date: September 23rd, 2020

DOI: https://doi.org/10.21203/rs.3.rs-76707/v1

License: (c) (i) This work is licensed under a Creative Commons Attribution 4.0 International License. Read Full License 
Version of Record: A version of this preprint was published at Radiation Oncology on April 16th, 2021. See the published version at https://doi.org/10.1186/s13014-021-01805-6. 


\section{Abstract}

Objectives: To generate and validate a state-of-the-art radiomics model for prediction of radiation-induced lung injury and oncologic outcome in non-small cell lung cancer (NSCLC) patients treated with robotic stereotactic body radiation therapy (SBRT).

Methods: A radiomics model was generated from the planning CT images of 110 patients with primary, inoperable stage I/Ila NSCLC who were treated with robotic SBRT using a risk-adapted fractionation scheme at the University Hospital Cologne (training cohort). In total, 851 radiomic features fulfilling the standards of the Image Biomarker Standardization Initiative (IBSI) were extracted from the outlined gross tumor volume (GTV) and used to build a model for prediction of local control (LC), disease-free survival (DFS), overall survival (OS) and development of local lung fibrosis (LF) by means of a gradient-boosted ensemble of regression trees. In addition, predictive clinical and dosimetric parameters were identified from a standard univariate Cox regression analysis. The radiomics model was validated in a comparable cohort of 71 patients treated by robotic SBRT at the Radiosurgery Center in Northern Germany (test cohort).

Results: Oncologic outcome did not differ between the two cohorts (OS at 36 months 56\% vs. 43\%, p=0.065; median DFS 25 months vs. 23 months, $p=0.43$; LC at 36 months $90 \%$ vs. 93\%, p=0.197). Local lung fibrosis developed in $33 \%$ vs. $35 \%$ of the patients $(p=0.75)$, all events were observed within 36 months. In the training cohort, the radiomics model was able to distinguish low-risk from high risk patients for OS, DFS, LC and LF with a high accuracy $(p<0.001)$. In the test cohort, the model for development of lung fibrosis retained its predictive power and could differentiate patients with a high risk for developing LF from those with a low risk $(p=0.016)$. In contrast, the radiomics model failed to predict OS, DFS and LC in the test cohort. Also, none of the clinical and dosimetric parameters predictive for

development of LF in the training cohort (GTV- $D_{\text {mean }}, G T V-D_{\text {max }}, P T V-D_{95 \%}$, Lung- $D_{1 m l}$, age) had a significant impact on the occurrence of LF in the test cohort.

Conclusion: Despite the obvious difficulties in generalizing predictive models for oncologic outcome and toxicity, this analysis shows that a carefully designed radiomics model for prediction of local lung fibrosis after SBRT of early stage lung cancer performs well across different institutions.

\section{Introduction}

Stereotactic body radiation therapy (SBRT) is an effective therapy for early-stage, node-negative, medically inoperable non-small cell lung cancer (NSCLC). Dose-fractionation schemes usually depend on tumor size and location and have been largely standardized by current guidelines [1-4]. However, after irradiation, about $10-15 \%$ of the tumors will recur locally and up to $50 \%$ of the patients will experience systemic disease progression despite PET-based staging before SBRT [5]. Also, 25-30\% of the patients will develop radiation-induced lung injury (RILI) on follow-up chest imaging, but apart from an established dose-response relationship for local control [6], dosimetric and clinical factors have only shown limited capability in predicting these events [7-14].

Radiomics aims at extraction of biomarkers from high-dimensional analysis of digital images and has been extensively studied in lung cancer by using computed tomography (CT) or Fluor-Deoxyglucose Positron Emission Tomography (FDG-PET) of the chest [15-20]. Several studies have applied radiomic analysis in SBRT of NSCLC [2134], but so far, the clinical impact of the developed algorithms has been low due to low reproducibility of the results [35], lack of standardization of the extracted radiomic features and lack of external validation on data from other institutions. 
The availability of open-source software solutions allows the extraction of standardized radiomic features and generation of complex, non-linear models which are able to account for complex interactions between features and have the potential to achieve high performance. In the present study, we applied state-of-the-art feature extraction and machine-learning algorithms in order to determine the extra value of imaging tumor biomarkers when used in addition to dosimetric and clinical factors for prediction of radiation-induced lung injury, local control, disease free survival and overall survival in a cohort of patients with NSCLC treated by robotic SBRT. The model was trained on data from one institution and tested on a cohort from a separate institution that treated patients based on similar inclusion criteria and fractionation schemes. This work extends an earlier single institution report [36].

\section{Patients And Methods}

\section{Patients, Treatment and Follow-Up}

Two cohorts of patients with stage I/Ila NSCLC (according to staging classification of the Union for International Cancer Control [UICC], $8^{\text {th }}$ edition) who underwent definitive robotic SBRT were retrospectively analyzed. The first cohort comprised 110 patients treated at the University Hospital of Cologne, Germany and was used for identification of clinical, dosimetric and image-derived parameters to predict local control (LC), overall survival (OS), disease free survival (DFS) and occurrence of local lung fibrosis (LF) as a manifestation of radiation-induced lung injury after SBRT. This cohort had already been analyzed in a previous study using a different radiomics approach [36] and served as the training data set. A second cohort of 71 patients was treated at the Radiosurgery Center Northern Germany, Guestrow, and was used as test set (in machine learning terminology) for the predictive power of the identified parameters in the training set.

In both cohorts, patients suffering from a peripheral T1/2 (UICC 8) NSCLC without lymph node metastases who were either medically inoperable or refused resection were treated solely by means of the Cyberknife ${ }^{R}$ system (Accuray, Sunnyvale, USA) without concomitant therapy using a risk-adapted fractionation scheme (peripheral T1 tumors 3x13$18 \mathrm{~Gy}$, T1 tumors with broad contact to the chest wall and T2 tumors 5x10-11Gy, near-central or true central tumors $8 \times 6-7.5 \mathrm{~Gy}$ ). The dose was calculated using the MonteCarlo dose calculation algorithm and prescription and reporting was done according to international recommendations [13; 37-40]. The cohorts also contained 12(8) patients with local stage T1/2 tumors who had been successfully treated for oligo-metastatic disease, and who were free from tumor activity besides the primary tumor. Patient characteristics and treatment parameters are shown in Tab.1. All patients had a planning CT which was used for both treatment planning and radiomics image analysis (Tab. 2).

Clinical and radiological follow-up including chest CT scans was scheduled at 3 and 6 months after radiotherapy and every 6 months thereafter. A local recurrence was assumed if the irradiated lesion showed a solid core that increased by at least $25 \%$ compared to the last follow-up and exhibited further growth. Every occurrence of diffuse or patchy consolidation, diffuse or patchy ground glass opacity or modified or mass like consolidation in the lung tissue adjacent to the tumor was regarded as radiation induced lung injury and termed local fibrosis [41; 42]. Lung tissue changes smaller than the original tumor, scar-like patterns distant to the tumor and lung toxicities without clear spatial or temporal relation to radiotherapy (early acute pneumonia, late acute pneumonia, pneumonitis spatially not correlated to the PTV) were not considered. Representative chest CT images are shown in Fig. 4. In cases where a growing lesion could not be differentiated from local fibrosis, a FDG-PET-CT scan or a biopsy was performed in order to confirm or reject the diagnosis of a local recurrence.

\section{Image processing and feature extraction}


Image processing was performed using Python 3.6.7 (Python Software Foundation, Beaverton, Oregon, USA). The original DICOM data containing manual delineations of the gross tumor volume (GTV) and anatomical image data were restored from the Cyberknife ${ }^{R}$ archive and subsequently used to extract the target volumes for radiomic analysis. For all further image processing, the software package pyradiomics 2.0.1 [43] was used that allows the extraction of standardized features which were defined by the IBSI (Image Biomarker Standardization Initiative) [44]. Preprocessing included resampling to isotropic voxel of $1 \mathrm{~mm}^{3}$ and removal of all pixels with Hounsfield units (HU) below (-400) HU and above $1000 \mathrm{HU}$ from the volume which were assumed to represent normal lung and bony tissue unintentionally included in the GTV. Radiomic features were calculated based on the original image and after wavelet filtering, yielding eight additional image types based on the application of wavelet-based high-pass or low-pass filters to each of the three dimensions. In addition to 14 features descriptive of the target's shape, 93 features were calculated for each of the nine image types, resulting in a total of 851 radiomic features.

\section{Model development and statistical analysis}

All model development was performed on the training cohort and the model parameters were optimized using crossvalidation schemes. First, the primary set of radiomics features was reduced by identifying and removing linearly correlated features with a Pearson correlation coefficient $>0.95$. Out of the 851 extracted features, 564 were found to be highly linearly correlated and removed from the analysis. The remaining 287 features were then used to develop predictive models for each of the four endpoints: LC, OS, DFS and occurrence of local lung fibrosis (LF) after SBRT. In order to maximize generalizability and allow for complex non-linear relationships between feature values and treatment outcome, a gradient-boosted ensemble of regression trees was chosen as model. The algorithm is implemented in scikit-survival package for Python [45] and learns to predict the individual (log) hazard ratios from a combination of the radiomics features similar to a linear predictor of a Cox proportional hazards model [46]. Within the training set, the parameters of the model were subjected to a grid search with 5 -fold cross-validation that regularized the depth of the regression trees (7), the learning rate (0.01) and the subset of features used for the next iteration (12 out of 287). The final radiomics model was then evaluated by means of the concordance index and by using the log hazard ratios as predictive factors in the training and test sets.

In addition to the radiomics features, the following continuous clinical and dosimetric variables were analyzed in univariate Cox regression models with respect to their potential impact on any of the endpoints: GTV (gross tumor volume), PTV (planning target volume), GTV-D $D_{\max }$ (maximal dose in GTV), GTV- $D_{\text {mean }}$ (mean dose in GTV), GTV-D ${ }_{95 \%}$ (dose achieved in $95 \%$ of the GTV), PTV- $D_{95 \%}$ (dose achieved in $95 \%$ of the PTV), Lung- $D_{1 \mathrm{ml}}$, Lung- $\mathrm{D}_{10 \mathrm{ml}}$, Lung- $\mathrm{D}_{50 \mathrm{ml}}$,

Lung- $\mathrm{D}_{100 \mathrm{~m}}$, tumor diameter, age and Charlson Comorbidity Score. Categorical clinical and treatment related factors were investigated using the Kaplan-Meier method and survival estimates were compared using two-sided log rank tests. These included: gender, T-Stage (T1 vs. T2), histology (squamous cell/ adeno /other/ unknown) and fiducial tracking (no/ yes). Finally, all radiomics, clinical and dosimetric factors with significant impact in univariate analysis were evaluated in a multivariate Cox regression model. All statistical analyses were performed with the software $\mathrm{R}$ (version 3.4.4; R Development Core Team) or SPSS (vs. 24, Armonk, NY, USA). A p-value of <0.05 was considered significant. The complete workflow is depicted in Figure 1.

\section{Results}

Clinical outcome 
The outcome in terms of the analyzed clinical endpoints did not differ significantly between the two cohorts (Fig. 2). Overall survival at 36 months amounted to $56 \%$ vs. $43 \%, p=0.065)$, median DFS was 25 months vs. 23 months, $p=0.43$ and local control rates at 36 months were $90 \%$ vs. $93 \%, p=0.197)$. In the training set, none of the clinical and dosimetric factors had a significant influence on the endpoints. Local lung fibrosis developed in $33 \%$ vs. $35 \%$ of the patients $(p=0.75)$, all events were observed within 36 months after irradiation. As shown in Tab. 3, three dosimetric factors $\left(G T V_{\text {mean }}, P T V-D_{95 \%}\right.$, Lung- $\left.D_{1 \mathrm{ml}}\right)$ and the patient's age had a significant impact on the development of local lung fibrosis with an increase in hazard of approximately $6 \%$ per Gy and per year of age. The direction and approximate size of these effects were also found in the test set but failed to reach statistical significance.

\section{Radiomics model}

In the training set, the algorithm was able to fit highly predictive models for all endpoints using the remaining 287 radiomic features, resulting in concordance indices of $0.997,0.996,0.996,0.998$ for OS, LC, development of lung fibrosis and DFS, respectively. Consequently, the radiomics predictor was able to distinguish low-risk from high risk patients (log hazard ratio $\leq 0$ vs. $>0$ ) for all of the endpoints OS, DFS, LC and LF with a high accuracy $(p<0.001$, Fig. 3). The radiomics predictor for LF retained its predictive value when analyzed together with $G_{T V} V_{\text {mean }}, P T V-D_{95 \%}$, Lung$\mathrm{D}_{1 \mathrm{ml}}$ and age in a multivariate Cox Regression model $(\mathrm{p}<0.001$, Tab. 3).

In the test cohort, the radiomics predictor was also able to differentiate patients with a high risk for developing LF from those with a low risk ( $p=0.016$, concordance index of 0.635 , Fig. 3 ). It also kept a significant influence in a multivariate Cox regression model with the above mentioned dosimetric factors and age included $(p<0.028)$. In contrast, the radiomics model failed to predict any of OS, DFS and LC in the test cohort (Tab. 3).

\section{Discussion}

\section{Summary of findings}

In the present analysis, two cohorts of early-stage lung cancer patients treated with robotic stereotactic body radiotherapy at two different institutions were investigated. Although slightly different fractionation schedules were applied, oncologic outcome in terms of local tumor control, disease-free survival and overall survival were well comparable. Importantly, the frequency and time course of development of radiation-induced local lung injury was also similar in the two cohorts. Radiomics analysis based on a set of standardized features and state-of-the-art modelling in the training cohort resulted in a model for prediction of radiation-induced local lung injury that performed well also in the test cohort and kept its predictive value when analyzed in conjunction with dosimetric parameters. However, the predictive models for the endpoints of oncologic outcome (OS, DFS, local control) failed to generalize to the test cohort.

\section{Prediction of local radiation-induced lung injury}

To the best of our knowledge, this is the first report that generated a predictive, general model for the development of local lung injury from the GTV after lung SBRT [36]. Radiation-induced local lung injury that finally develops into local lung fibrosis is a typical event after lung SBRT, although it remains asymptomatic in most cases. It is probably triggered by the release of inflammatory cytokines such as TGF-ß from the tumor which subsequently initiate an immunological response [47; 48]. At first sight, it seems far from obvious how a texture pattern detectable by radiomics could predict for this event. However, an association between a pre-therapeutic radiomics feature (LoG standard deviation) with the TGF- $ß$ signaling pathway has recently been observed, and in the same report, a radiomics score was correlated with the amount of tumor infiltration by T-lymphocytes [49]. The view that image features 
correlate with the presence of immune-competent cells in lung tumor tissue is also supported by the observation that lung tumors characterized by low CT intensity and high CT heterogeneity exhibited a high CD3 (T-lymphocyte) infiltration, suggestive of an activated immune state [50].

In the present report, the radiomics model kept its predictive value for the development of lung fibrosis in both cohorts even when analyzed in a comprehensive model including dosimetric factors of the target volumes and adjacent lung

(GTV-D $D_{\text {mean }}$, GTV-D $D_{\text {max }}$, PTV-D $95 \%$, Lung- $D_{1 \mathrm{ml}}$ ) although the predictive ability of the dosimetric factors could not be reproduced in the test cohort. In a comparable approach that has been applied for prediction of radiation pneumonitis from features of the total lung tissue in lung cancer patients treated with intensity-modulated radiotherapy (IMRT), the radiomics features only slightly improved the predictive value of the model when added to clinical and dosimetric factors [47]. Interestingly, the inhomogeneous dose distribution usually generated by robotic radiosurgery and volumetric arc therapy has itself been analyzed with respect to dose distribution patterns ("dosiomics") which in turn have been found to predict the incidence of radiation pneumonitis [51]. Thus, a more comprehensive model of radiation-induced lung injury could probably be built from incorporating texture analysis of the tumor, a shell [52; 53] comprising the adjacent lung tissue and the dose distribution.

\section{Prediction of local control, disease-free survival and overall survival}

Although the two cohorts resembled each other in terms of oncologic outcome, the radiomics model did not generalize from the training to the test cohort with respect to these endpoints. A compilation of recent studies on the impact of radiomics features on oncologic outcome for lung cancer patients after SBRT is presented in Tab. 4. Most of the studies applied single institution cross-validation or validation by test sets from the same institution and were able to predict local tumor recurrence, regional/nodal recurrence, distant failures and overall survival with a moderate accuracy. Of note, one report failed to observe features predictive of local recurrence [24]. Only in a minority of series were the results validated in test sets from independent institutions. In a large study from the Cleveland Clinic (Ohio, USA), a convolutional neural network (CNN) was trained to predict local recurrence in a group of $>900$ lung cancer patients treated by SBRT. The stratification resulted in two groups with highly significant different risk for recurrence in both the training and test set [54]. Also in another study where a CNN was applied to both CT and PET images, a highly accurate classification of survival probability was achieved in an independent data set [21].

\section{Limitations Of The Present Study}

The present study, although based on the results of two independent cohorts, probably still lacks a sufficient number of patients needed for an informative analysis of the interaction between dosimetric parameters and radiologic tissue characteristics for prediction of local events (recurrence, local lung fibrosis) after SBRT of NSCLC. Also, the classification of local lung injury and tumor control is purely image-based and remains somewhat ambiguous, as tissue specimens are rarely available following SBRT. Differences in therapeutic strategies for detecting and treating metastases may have prevented the creation of a general radiomics-based model for prediction of DFS and OS.

\section{Conclusions}

The present analysis provides evidence that radiomics analysis can, in principle, be used for prediction of local lung injury after SBRT of NSCLC in independent data sets and as such complements existing results on the successful prediction of other oncologic endpoints in this setting.

\section{Abbreviations}


NSCLC: Non-Small Cell Lung Cancer

SBRT: Stereotactic Body Radiation Therapy

RILI: Radiation-Induced Lung Injury

UICC: Union for International Cancer Control

LC: Local Control

DFS: Disease-Free Survival

OS: Overall survival

LF: Lung Fibrosis

GTV: Gross Tumor Volume

PTV: Planning Target Volume

GTV-D $D_{\text {mean }}$ : Mean Dose in GTV

GTV-D $D_{\text {max }}:$ Maximal Dose in GTV

PTV- D $_{95 \%}$ : Dose covering $95 \%$ of the PTV

GTV-D $95 \%$ : Dose covering $95 \%$ of the GTV

Lung- $\mathrm{D}_{1 \mathrm{ml}}$ : Dose achieved in $1 \mathrm{ml}$ of the lung volume

Lung- $\mathrm{D}_{10 \mathrm{ml}}$ : Dose achieved in $10 \mathrm{ml}$ of the lung volume

CT: Computed Tomography

PET: Positron Emission Tomography

FDG-PET: Fluor-Deoxyglucose-Positron Emission Tomograpy

DICOM: Digital Imaging and Communications in Medicine

HU: Hounsfield Unit

IBSI: Image Biomarker Standardization Initiative

CNN: Convolutional Neural Network

LoG: Laplacian-of Gaussian

TGF-ß: Transforming Growth Factor beta

CD3: Cluster of Differentiation (protein) 3 


\section{Declarations}

\section{Ethical Approval and Consent to participate}

This study was approved by the Ethics Committee of the Medical Faculty, University of Cologne, protocol number 17009 and by the Ethics Committee of the Medical Faculty, University of Kiel, protocol number D421/18. All data were processed in anonymized form. Individual informed consent was waived as this was a retrospective study.

\section{Consent for publication}

Not applicable

\section{Competing interests}

The authors declare that they have no competing interests

\section{Availability of supporting data}

The datasets generated and/or analysed during the current study are not publicly available due but are available from the corresponding author on reasonable request

\section{Funding}

The present work received no funding

\section{Authors' contributions}

KB: design, data acquisition, data analysis, data interpretation, manuscript draft

OB: conception, design, data acquisition, data analysis, data interpretation, manuscript draft

ST: data acquisition, data interpretation, manuscript draft

MLW: data acquisition, data interpretation, manuscript draft

$\mathrm{MH}$ : data analysis, data interpretation, manuscript draft

WWB: data aquisition, data interpretation, manuscript draft

DR: data interpretation, manuscript draft

VVV: data interpretation, manuscript draft

MIR: data interpretation, manuscript draft

$\mathrm{HT}$ : conception, design, data interpretation, manuscript draft

MK: conception, design, data acquisition, data analysis, data interpretation, manuscript draft 
all: approved the submitted version

all: agreed both to be personally accountable for the author's own contributions

and to ensure that questions related to the accuracy or integrity of any part of

the work, even ones in which the author was not personally involved, are

appropriately investigated, resolved, and the resolution documented in the

literature

\section{Acknowledgements}

None

\section{Authors' information (Optional)}

None

\section{References}

1 NCCN (2019) National Comprehensive Cancer Network: Non Small-Cell Lung Cancer. NCCN Clinical Practice Guidelines in Oncology (NCCN Guidelines):Version 7.2019

2 Guckenberger M, Aerts JG, Van Schil P, Weder W (2019) The American Society of Clinical Oncology-endorsed American Society for Radiation Oncology Evidence-Based Guideline of stereotactic body radiotherapy for early-stage non-small cell lung cancer: An expert opinion. J Thorac Cardiovasc Surg 157:358-361

3 Guckenberger M, Andratschke N, Alheit H et al (2014) Definition of stereotactic body radiotherapy: principles and practice for the treatment of stage I non-small cell lung cancer. Strahlenther Onkol 190:26-33

4 Guckenberger M, Andratschke N, Dieckmann K et al (2017) ESTRO ACROP consensus guideline on implementation and practice of stereotactic body radiotherapy for peripherally located early stage non-small cell lung cancer.

Radiother Oncol 124:11-17

5 Febbo JA, Gaddikeri RS, Shah PN (2018) Stereotactic Body Radiation Therapy for Early-Stage Non-Small Cell Lung Cancer: A Primer for Radiologists. Radiographics 38:1312-1336

6 Guckenberger M, Klement RJ, Allgauer M et al (2016) Local tumor control probability modeling of primary and secondary lung tumors in stereotactic body radiotherapy. Radiother Oncol 118:485-491

7 Guckenberger M, Klement RJ, Kestin LL et al (2013) Lack of a dose-effect relationship for pulmonary function changes after stereotactic body radiation therapy for early-stage non-small cell lung cancer. Int J Radiat Oncol Biol Phys 85:1074-1081

8 Okubo M, Itonaga T, Saito T et al (2017) Predicting risk factors for radiation pneumonitis after stereotactic body radiation therapy for primary or metastatic lung tumours. Br J Radiol 90:20160508

9 Zhao J, Yorke ED, Li L et al (2016) Simple Factors Associated With Radiation-Induced Lung Toxicity After Stereotactic Body Radiation Therapy of the Thorax: A Pooled Analysis of 88 Studies. Int J Radiat Oncol Biol Phys 
10 Knoll MA, Salvatore M, Sheu RD et al (2016) The use of isodose levels to interpret radiation induced lung injury: a quantitative analysis of computed tomography changes. Quant Imaging Med Surg 6:35-41

11 Inoue T, Shiomi H, Oh RJ (2015) Stereotactic body radiotherapy for Stage I lung cancer with chronic obstructive pulmonary disease: special reference to survival and radiation-induced pneumonitis. J Radiat Res 56:727-734

12 Ricardi U, Filippi AR, Guarneri A et al (2009) Dosimetric predictors of radiation-induced lung injury in stereotactic body radiation therapy. Acta Oncol 48:571-577

13 Baumann R, Chan MKH, Pyschny F et al (2018) Clinical Results of Mean GTV Dose Optimized Robotic-Guided Stereotactic Body Radiation Therapy for Lung Tumors. Front Oncol 8:171

14 Nakamura M, Nishikawa R, Mayahara H et al (2019) Pattern of recurrence after CyberKnife stereotactic body radiotherapy for peripheral early non-small cell lung cancer. $\mathrm{J}$ Thorac Dis 11:214-221

15 Aerts HJ, Velazquez ER, Leijenaar RT et al (2014) Decoding tumour phenotype by noninvasive imaging using a quantitative radiomics approach. Nat Commun 5:4006

16 Coroller TP, Agrawal V, Huynh E et al (2017) Radiomic-Based Pathological Response Prediction from Primary Tumors and Lymph Nodes in NSCLC. J Thorac Oncol 12:467-476

17 Coroller TP, Agrawal V, Narayan V et al (2016) Radiomic phenotype features predict pathological response in nonsmall cell lung cancer. Radiother Oncol 119:480-486

18 Coroller TP, Grossmann P, Hou Y et al (2015) CT-based radiomic signature predicts distant metastasis in lung adenocarcinoma. Radiother Oncol 114:345-350

19 Grove O, Berglund AE, Schabath MB et al (2015) Quantitative computed tomographic descriptors associate tumor shape complexity and intratumor heterogeneity with prognosis in lung adenocarcinoma. PLoS One 10:e0118261

20 Lee G, Lee HY, Park H et al (2017) Radiomics and its emerging role in lung cancer research, imaging biomarkers and clinical management: State of the art. Eur J Radiol 86:297-307

21 Baek S, He Y, Allen BG et al (2019) Deep segmentation networks predict survival of non-small cell lung cancer. Sci Rep 9:17286

22 Dissaux G, Visvikis D, Do-Ano R et al (2019) Pre-treatment (18)F-FDG PET/CT Radiomics predict local recurrence in patients treated with stereotactic radiotherapy for early-stage non-small cell lung cancer: a multicentric study. J Nucl Med. 10.2967/jnumed.119.228106

23 Franceschini D, Cozzi L, De Rose F et al (2019) A radiomic approach to predicting nodal relapse and diseasespecific survival in patients treated with stereotactic body radiation therapy for early-stage non-small cell lung cancer. Strahlenther Onkol. 10.1007/s00066-019-01542-6

24 Huynh E, Coroller TP, Narayan V et al (2016) CT-based radiomic analysis of stereotactic body radiation therapy patients with lung cancer. Radiother Oncol 120:258-266 
25 Huynh E, Coroller TP, Narayan V et al (2017) Associations of Radiomic Data Extracted from Static and RespiratoryGated CT Scans with Disease Recurrence in Lung Cancer Patients Treated with SBRT. PLoS One 12:e0169172

26 Lafata KJ, Hong JC, Geng R et al (2019) Association of pre-treatment radiomic features with lung cancer recurrence following stereotactic body radiation therapy. Phys Med Biol 64:025007

27 Li H, Galperin-Aizenberg M, Pryma D, Simone CB, 2nd, Fan Y (2018) Unsupervised machine learning of radiomic features for predicting treatment response and overall survival of early stage non-small cell lung cancer patients treated with stereotactic body radiation therapy. Radiother Oncol 129:218-226

28 Li Q, Kim J, Balagurunathan Y et al (2017) Imaging features from pretreatment CT scans are associated with clinical outcomes in nonsmall-cell lung cancer patients treated with stereotactic body radiotherapy. Med Phys 44:4341-4349

29 Li Q, Kim J, Balagurunathan Y et al (2017) CT imaging features associated with recurrence in non-small cell lung cancer patients after stereotactic body radiotherapy. Radiat Oncol 12:158

30 Li S, Yang N, Li B et al (2018) A pilot study using kernelled support tensor machine for distant failure prediction in lung SBRT. Med Image Anal 50:106-116

31 Oikonomou A, Khalvati F, Tyrrell PN et al (2018) Radiomics analysis at PET/CT contributes to prognosis of recurrence and survival in lung cancer treated with stereotactic body radiotherapy. Sci Rep 8:4003

32 Starkov P, Aguilera TA, Golden DI et al (2019) The use of texture-based radiomics CT analysis to predict outcomes in early-stage non-small cell lung cancer treated with stereotactic ablative radiotherapy. $\mathrm{Br} \mathrm{J}$ Radiol 92:20180228

33 Takeda K, Takanami K, Shirata Y et al (2017) Clinical utility of texture analysis of 18F-FDG PET/CT in patients with Stage I lung cancer treated with stereotactic body radiotherapy. J Radiat Res. 10.1093/jrr/rrx050:1-8

34 Yu W, Tang C, Hobbs BP et al (2017) Development and Validation of a Predictive Radiomics Model for Clinical Outcomes in Stage I Non-small Cell Lung Cancer. Int J Radiat Oncol Biol Phys. 10.1016/j.jirobp.2017.10.046

35 van Timmeren JE, Carvalho S, Leijenaar RTH et al (2019) Challenges and caveats of a multi-center retrospective radiomics study: an example of early treatment response assessment for NSCLC patients using FDG-PET/CT radiomics. PLoS One 14:e0217536

36 Bousabarah K, Temming S, Hoevels M et al (2019) Radiomic analysis of planning computed tomograms for predicting radiation-induced lung injury and outcome in lung cancer patients treated with robotic stereotactic body radiation therapy. Strahlenther Onkol 195:830-842

37 Schmitt D, Blanck O, Gauer T et al (2020) Technological quality requirements for stereotactic radiotherapy : Expert review group consensus from the DGMP Working Group for Physics and Technology in Stereotactic Radiotherapy. Strahlenther Onkol 196:421-443

38 Stera S, Balermpas P, Chan MKH et al (2018) Breathing-motion-compensated robotic guided stereotactic body radiation therapy : Patterns of failure analysis. Strahlenther Onkol 194:143-155

39 Temming S, Kocher M, Stoelben E et al (2018) Risk-adapted robotic stereotactic body radiation therapy for inoperable early-stage non-small-cell lung cancer. Strahlenther Onkol 194:91-97

Page $12 / 21$ 
40 Wilke L, Andratschke N, Blanck $O$ et al (2019) ICRU report 91 on prescribing, recording, and reporting of stereotactic treatments with small photon beams : Statement from the DEGRO/DGMP working group stereotactic radiotherapy and radiosurgery. Strahlenther Onkol 195:193-198

41 Dahele M, Palma D, Lagerwaard F, Slotman B, Senan S (2011) Radiological changes after stereotactic radiotherapy for stage I lung cancer. J Thorac Oncol 6:1221-1228

42 Trovo M, Linda A, El Naqa I, Javidan-Nejad C, Bradley J (2010) Early and late lung radiographic injury following stereotactic body radiation therapy (SBRT). Lung Cancer 69:77-85

43 Van Griethuysen JJ, Fedorov A, Parmar C et al (2017) Computational radiomics system to decode the radiographic phenotype. Cancer research 77:e104-e107

44 Zwanenburg A, Leger S, Löck S (2016) Image biomarker standardisation initiative.

http://arxivorg/abs/161207003:Accessed January 2, 2020

45 Pölsterl S, Gupta P, Wang L, Conjeti S, Katouzian A, Navab N (2016) Heterogeneous ensembles for predicting survival of metastatic, castrate-resistant prostate cancer patients. F1000Research 5

46 Cox DR (1972) Regression models and life-tables. Journal of the Royal Statistical Society: Series B (Methodological) 34:187-202

47 Tsoutsou PG, Koukourakis MI (2006) Radiation pneumonitis and fibrosis: mechanisms underlying its pathogenesis and implications for future research. Int J Radiat Oncol Biol Phys 66:1281-1293

48 Wang S, Campbell J, Stenmark MH et al (2017) Plasma Levels of IL-8 and TGF-beta1 Predict Radiation-Induced Lung Toxicity in Non-Small Cell Lung Cancer: A Validation Study. Int J Radiat Oncol Biol Phys 98:615-621

49 Grossmann P, Stringfield O, El-Hachem N et al (2017) Defining the biological basis of radiomic phenotypes in lung cancer. Elife 6:e23421

50 Tang C, Hobbs B, Amer A et al (2018) Development of an Immune-Pathology Informed Radiomics Model for NonSmall Cell Lung Cancer. Sci Rep 8:1922

51 Liang B, Yan H, Tian Y et al (2019) Dosiomics: Extracting 3D Spatial Features From Dose Distribution to Predict Incidence of Radiation Pneumonitis. Front Oncol 9:269

52 Diamant A, Chatterjee A, Faria S et al (2018) Can dose outside the PTV influence the risk of distant metastases in stage I lung cancer patients treated with stereotactic body radiotherapy (SBRT)? Radiother Oncol.

10.1016/j.radonc.2018.05.012

$53 \mathrm{Hao} \mathrm{H}$, Zhou Z, Li S et al (2018) Shell feature: a new radiomics descriptor for predicting distant failure after radiotherapy in non-small cell lung cancer and cervix cancer. Phys Med Biol 63:095007

54 Lou B, Doken S, Zhuang T et al (2019) An image-based deep learning framework for individualizing radiotherapy dose. Lancet Digit Health 1:e136-e147

55 Zhang Y, Oikonomou A, Wong A, Haider MA, Khalvati F (2017) Radiomics-based Prognosis Analysis for Non-Small Cell Lung Cancer. Sci Rep 7:46349

Page $13 / 21$ 
56 Luo Y, McShan DL, Matuszak MM et al (2018) A multiobjective Bayesian networks approach for joint prediction of tumor local control and radiation pneumonitis in nonsmall-cell lung cancer (NSCLC) for response-adapted radiotherapy. Med Phys. 10.1002/mp.13029

\section{Tables}

Tab. 1 Patient and treatment characteristics

$$
\begin{array}{ll}
\begin{array}{l}
\text { Training Set } \\
(n=110)
\end{array} & \begin{array}{l}
\text { Test Set } \\
(n=71)
\end{array}
\end{array}
$$

\begin{tabular}{lllll}
\hline Age & $73 y$ & $(50-94 \mathrm{y})$ & $75 \mathrm{y}$ & $(48-88 \mathrm{y})$ \\
Gender (male/female) & $58 / 52$ & $(53 \% / 47 \%)$ & $47 / 24$ & $(66 \% / 34 \%)$ \\
Tumor diameter (median/range) & $2.2 \mathrm{~cm}(0.8-6.6 \mathrm{~cm})^{*}$ & $2.6 \mathrm{~cm}(1.1-6.0 \mathrm{~cm})^{*}$ \\
Tumor Stage (UICC8), T1/T2 & $89 / 21 \quad(81 \% / 19 \%)$ & $45 / 26$ & $(63 \% / 37 \%)$ \\
Pathological confirmation yes / no & $91 / 19$ & $(83 \% / 17 \%)$ & $55 / 16$ & $(77 \% / 23 \%)$
\end{tabular}

\section{Mediastinal Staging:}

$\begin{array}{lcc}\text { CT only } & 18(16 \%) & 5(7 \%) \\ \text { CT + PET } & 52(47 \%) & 33(47 \%) \\ \text { CT + EBUS } & 18(16 \%) & 16(23 \%) \\ \text { CT + EBUS + PET } & 18(16 \%) & 17(24 \%) \\ \text { CT + Mediastinoscopy } & 3(3 \%) & - \\ \text { CT + PET + Mediastinoscopy } & 1(1 \%) & -\end{array}$

\section{Histology:}

Adenocarcinoma

$37(34 \%) \quad 23(32 \%)$

Squamous Cell

other

$42(38 \%)$

$12(11 \%)$

unknown

$19(17 \%)$

\section{Fractionation scheme:}

Number of fractions
1
3
5
8

GTV-PTV margin

\section{Tracking mode:}

Fiducials/ XSightLung

* 1 pt. $>5 \mathrm{~cm}$

* 3 pts. $>5 \mathrm{~cm}$

$\$ 1$ pt. $4 \times 10 \mathrm{~Gy}$

$$
\begin{array}{ll}
\text { dose } & n \\
25 \mathrm{~Gy} & 5(5 \%) \\
17 \mathrm{~Gy} & 45(41 \%) \\
11 \mathrm{~Gy} & 43(39 \%) \\
7.5 \mathrm{~Gy} & 17(16 \%)
\end{array}
$$

3-4 mm

$15 / 95$ (14\%/86\%)

$\begin{array}{lc}\text { dose } & n \\ 26-27 G y & 2(3 \%) \\ 13-18 G y & 65(90 \%)^{\S} \\ 10-11 G y & 3(6 \%) \\ 6 \text { Gy } & 1(1 \%)\end{array}$

$3-5 \mathrm{~mm}$

$6 / 65(9 \% / 91 \%)$

Tab. 2 Imaging parameters 


$\begin{array}{lll}\text { CT scanner } & \text { Aquilion LB-CT, Toshiba } & \text { Brilliance 16, Philips } \\ \text { Slice thickness } & 1.0 \mathrm{~mm} & 1.5 \mathrm{~mm} \\ \text { Transversal resolution } & 0.93-1.37 \mathrm{~mm} & 0.93-0.97 \mathrm{~mm} \\ \text { Voltage } & 120 \mathrm{KV} & 120 \mathrm{KV} \\ \text { Current-time product } & 400 \mathrm{mAs} & 400-450 \mathrm{mAs} \\ \text { Image matrix } & 512 \times 512 & 512 \times 512 \\ \text { Reconstruction kernel } & \text { FC17 } & \text { B } \\ \text { Contrast agent } & \text { none }(84 \%), & \text { none }(100 \%) \\ & \text { Accupaque } 300(16 \%)^{*} & \end{array}$

* no significant impact on GTV radiodensity

Tab. 3 Factors for developing local lung fibrosis

\begin{tabular}{|c|c|c|c|c|}
\hline Factor & $\begin{array}{l}\text { Training Set } \\
\text { Mean }\end{array}$ & $\begin{array}{l}\text { Training Set } \\
\text { Hazard Ratio }\end{array}$ & $\begin{array}{l}\text { Test Set } \\
\text { Mean }\end{array}$ & $\begin{array}{l}\text { Test Set } \\
\text { Hazard Ratio }\end{array}$ \\
\hline GTV $D_{\text {mean }}$ & 69.5 Gy & $1.058 *$ & 61.6 Gy & 1.064 \\
\hline PTV $D_{95}$ & $52.8 \mathrm{~Gy}$ & $1.063^{\star}$ & 45.4 Gy & 1.075 \\
\hline $\mathrm{D}_{1 \mathrm{ml}}$ Lung & $64.1 \mathrm{~Gy}$ & $1.056 *$ & 55.9 Gy & 1.060 \\
\hline Age & $71.9 \mathrm{y}$ & $1.062 *$ & 74.6 y & 1.044 \\
\hline $\begin{array}{l}\text { Radiomics- } \\
\text { Predictor (low/high) } \\
\text { univariate }\end{array}$ & 0.0 & $31.65^{\star \star \star}$ & 0.5 & $3.32^{\star}$ \\
\hline $\begin{array}{l}\text { Radiomics- } \\
\text { Predictor (low/high) } \\
\text { multivariate }\end{array}$ & 0.0 & $41.95^{\star \star \star}$ & 0.7 & $2.05^{\star}$ \\
\hline
\end{tabular}

$\star p<0.05,{ }^{* \star *} p<0.001$ in univariate/multivariate Cox Regression analysis

Tab. 4 Reports on outcome prediction of SBRT in lung cancer from analysis of radiomic features 


\begin{tabular}{|c|c|c|c|c|c|c|c|}
\hline Author & $\mathbf{N}$ & $\begin{array}{l}\text { Modality/ } \\
\text { Features } \\
\text { (Software } \\
\text { applied) }\end{array}$ & $\begin{array}{l}\text { \# features } \\
\text { selected }\end{array}$ & Model Type & $\begin{array}{l}\text { Outcome } \\
\text { Measures }\end{array}$ & Validation & $\begin{array}{l}\text { Result/ } \\
\text { Comment }\end{array}$ \\
\hline $\begin{array}{l}\text { Huynh [24] } \\
(2016)\end{array}$ & 113 & $\begin{array}{l}\text { CT:1605 } \\
\text { (in-house } \\
\text { software) }\end{array}$ & $\begin{array}{l}12 \\
+ \text { clinical }\end{array}$ & $\begin{array}{l}\text { Survival } \\
\text { Analysis, } \\
\text { cc-index }\end{array}$ & $\begin{array}{l}\text { Recurrence, } \\
\text { Distant } \\
\text { mets., OS }\end{array}$ & $\begin{array}{l}\text { Single } \\
\text { institution } \\
\text { cross } \\
\text { validation }\end{array}$ & $\begin{array}{l}\text { Risk for } \\
\text { recurrence: } \\
\text { no } \\
\text { significant } \\
\text { features } \\
\\
\text { Risk for dist. } \\
\text { metastases: } \\
1 \text { sign. } \\
\text { feature } \\
\text { OS: } 4 \\
\text { significant } \\
\text { features, cc = } \\
0.67\end{array}$ \\
\hline $\begin{array}{l}\text { Li [28; 29] } \\
(2017)\end{array}$ & 92 & $\begin{array}{l}\text { CT: } 219 \\
\text { (Definiens } \\
\text { Developer) }\end{array}$ & $\begin{array}{l}8-68 \\
+ \text { clinical } \\
+ \\
\text { semantic }\end{array}$ & $\begin{array}{l}\text { ROC- } \\
\text { Analysis }\end{array}$ & $\begin{array}{l}\text { Recurrence, } \\
\text { RFS, OS }\end{array}$ & $\begin{array}{l}\text { Single } \\
\text { institution } \\
\text { cross- } \\
\text { validation }\end{array}$ & $\begin{array}{l}\text { Risk } \\
\text { stratification: } \\
\text { AUC }=0.69- \\
0.75\end{array}$ \\
\hline $\begin{array}{l}\text { Zhang [55] } \\
(2017)\end{array}$ & 112 & $\begin{array}{l}\text { CT: } 30 \\
\text { (ProCanVAS) }\end{array}$ & $\begin{array}{l}\text { dependent } \\
\text { on model }\end{array}$ & $\begin{array}{l}8 \text { models: } \\
\text { Random } \\
\text { forest } \\
\text { GLM, SVM } \\
\text { etc. }\end{array}$ & $\begin{array}{l}\text { Recurrence, } \\
\text { Distal } \\
\text { failure, } \\
\text { OS }\end{array}$ & $\begin{array}{l}\text { Single } \\
\text { institution } \\
\text { cross } \\
\text { validation }\end{array}$ & $\begin{array}{l}\text { Risk } \\
\text { stratification: } \\
\text { AUC }=0.60 \text { - } \\
0.77\end{array}$ \\
\hline $\begin{array}{l}\text { Yu [34] } \\
(2017)\end{array}$ & 442 & $\begin{array}{l}\text { CT: } 12 \\
\text { (IBEX) }\end{array}$ & 2 & $\begin{array}{l}\text { Random } \\
\text { Survival } \\
\text { Forests }\end{array}$ & $\begin{array}{l}\text { Regional } \\
\text { recurrence, } \\
\text { os }\end{array}$ & $\begin{array}{l}\text { Single } \\
\text { institution } \\
\text { test set: } \\
67 \%\end{array}$ & $\begin{array}{l}\text { OS risk } \\
\text { stratification: } \\
p=0.017 \\
\text { Recurrence } \\
\text { risk } \\
\text { stratification: } \\
p<0.05 \\
2 \text { sign. } \\
\text { features: } \\
\text { kurtosis, } \\
\text { homogeneity }\end{array}$ \\
\hline $\begin{array}{l}\text { Li [30] } \\
(2018)\end{array}$ & 110 & $\begin{array}{l}\text { CT+ FDG- } \\
\text { PET } \\
\text { (learned by } \\
\text { model) }\end{array}$ & $\begin{array}{l}\text { from } \\
\text { model }\end{array}$ & $\begin{array}{l}\text { Kernelled } \\
\text { support } \\
\text { tensor } \\
\text { machine }\end{array}$ & $\begin{array}{l}\text { Distant } \\
\text { failure }\end{array}$ & $\begin{array}{l}\text { Single } \\
\text { institution } \\
\\
\text { test set: } \\
30 \%\end{array}$ & $\begin{array}{l}\text { Risk } \\
\text { stratification: } \\
\text { AUC }=0.80\end{array}$ \\
\hline $\begin{array}{l}\text { Oikonomou } \\
\text { (2018) [31] }\end{array}$ & 150 & $\begin{array}{l}\mathrm{CT}+\mathrm{FDG}- \\
\mathrm{PET} \\
2 \times 21 \\
\text { (ProCanVAS) }\end{array}$ & $\begin{array}{l}6-8 \\
4 \text { from } \\
\text { PCA }\end{array}$ & $\begin{array}{l}\text { PCA, } \\
\text { Logistic } \\
\text { Regression }\end{array}$ & $\begin{array}{l}\text { Local } \\
\text { control, } \\
\text { Distant } \\
\text { control, } \\
\text { DSS, OS }\end{array}$ & $\begin{array}{l}\text { Single } \\
\text { institution } \\
\text { cross } \\
\text { validation }\end{array}$ & $\begin{array}{l}\text { Risk } \\
\text { stratification: } \\
p=0.004- \\
0.02 \\
\text { features: } \\
\text { heterogeneity } \\
\text { and } \\
\text { morphology }\end{array}$ \\
\hline $\begin{array}{l}\text { Starkov [32] } \\
(2019)\end{array}$ & 116 & $\begin{array}{l}\text { CT: 2D- } \\
\text { textures } \\
\text { from solid } \\
\text { core and } \\
\text { GGO }\end{array}$ & $2-30$ & $\begin{array}{l}\text { Cox } \\
\text { Regression } \\
\text { Lasso }\end{array}$ & $\begin{array}{l}\text { PFS, } \\
\text { Distant } \\
\text { failure }\end{array}$ & $\begin{array}{l}\text { Single } \\
\text { institution } \\
\text { cross } \\
\text { validation }\end{array}$ & $\begin{array}{l}\text { Risk } \\
\text { stratification: } \\
p=0.03 \\
\text { dependent } \\
\text { on wavelet } \\
\text { filtering }\end{array}$ \\
\hline
\end{tabular}




\begin{tabular}{|c|c|c|c|c|c|c|c|}
\hline $\begin{array}{l}\text { Lafata [26] } \\
(2019)\end{array}$ & 70 & CT: 43 & 2 & $\begin{array}{l}\text { Logistic } \\
\text { Regression } \\
\text { Regularized }\end{array}$ & $\begin{array}{l}\text { Local } \\
\text { recurrence }\end{array}$ & none & $\begin{array}{l}\text { Risk } \\
\text { stratification: } \\
p=0.048 \\
\text { features: } \\
\text { density }\end{array}$ \\
\hline $\begin{array}{l}\text { Franceschini } \\
\text { (2019) [23] }\end{array}$ & 102 & $\begin{array}{l}\text { CT: } 41 \\
\text { (LifeX) }\end{array}$ & $4-6$ & $\begin{array}{l}\text { Cox } \\
\text { Regression } \\
\text { Elastic Net, } \\
\text { Back } \\
\text { selection }\end{array}$ & $\begin{array}{l}\text { Nodal } \\
\text { relapse, } \\
\text { PFS, DSS }\end{array}$ & $\begin{array}{l}\text { Single } \\
\text { institution } \\
\text { Test set: } \\
32 \%\end{array}$ & $\begin{array}{l}\text { Nodal } \\
\text { Relapse: } \\
\text { Accuracy = } \\
85 \% \\
\text { PFS: } 53 \\
\text { vs.45 } \\
\text { months } \\
\text { features: } \\
\text { heterogeneity }\end{array}$ \\
\hline $\begin{array}{l}\text { Lou [56] } \\
(2019)\end{array}$ & $944 *$ & CT & $\begin{array}{l}\text { learned by } \\
\text { model }\end{array}$ & $\begin{array}{l}\text { CNN, } \\
\text { Multivariate } \\
\text { competing } \\
\text { risk }\end{array}$ & $\begin{array}{l}\text { Local } \\
\text { recurrence }\end{array}$ & $\begin{array}{l}\text { Multi } \\
\text { institution } \\
\text { Test set: } \\
10 \%\end{array}$ & $\begin{array}{l}\text { Risk } \\
\text { stratification: } \\
p<0.002\end{array}$ \\
\hline $\begin{array}{l}\text { Baek [21] } \\
(2019)\end{array}$ & 122 & $\begin{array}{l}\text { CT + FDG- } \\
\text { PET } \\
2 \times 55296\end{array}$ & $\begin{array}{l}\text { Features } \\
\text { from } \\
\text { k-medoids } \\
\text { pool }\end{array}$ & $\begin{array}{l}\text { CNN (U- } \\
\text { Net) } \\
\text { Logistic } \\
\text { regression }\end{array}$ & OS & $\begin{array}{l}\text { Independent } \\
\text { institution } \\
\text { Test set: } \\
21 \%\end{array}$ & $\begin{array}{l}\text { Risk } \\
\text { stratification: } \\
\text { AUC = } 0.87\end{array}$ \\
\hline
\end{tabular}

* includes recurrent lung cancers and pulmonary metastases; \# features from PET and CT; ProCanVAS: Prostate Cancer Visualization and Analysis System; PCA: Principal Component Analysis; cc-index: concordance index; RFS: Recurrence-free survival; ROC: Receiver-Operator-Characteristics

\section{Figures}




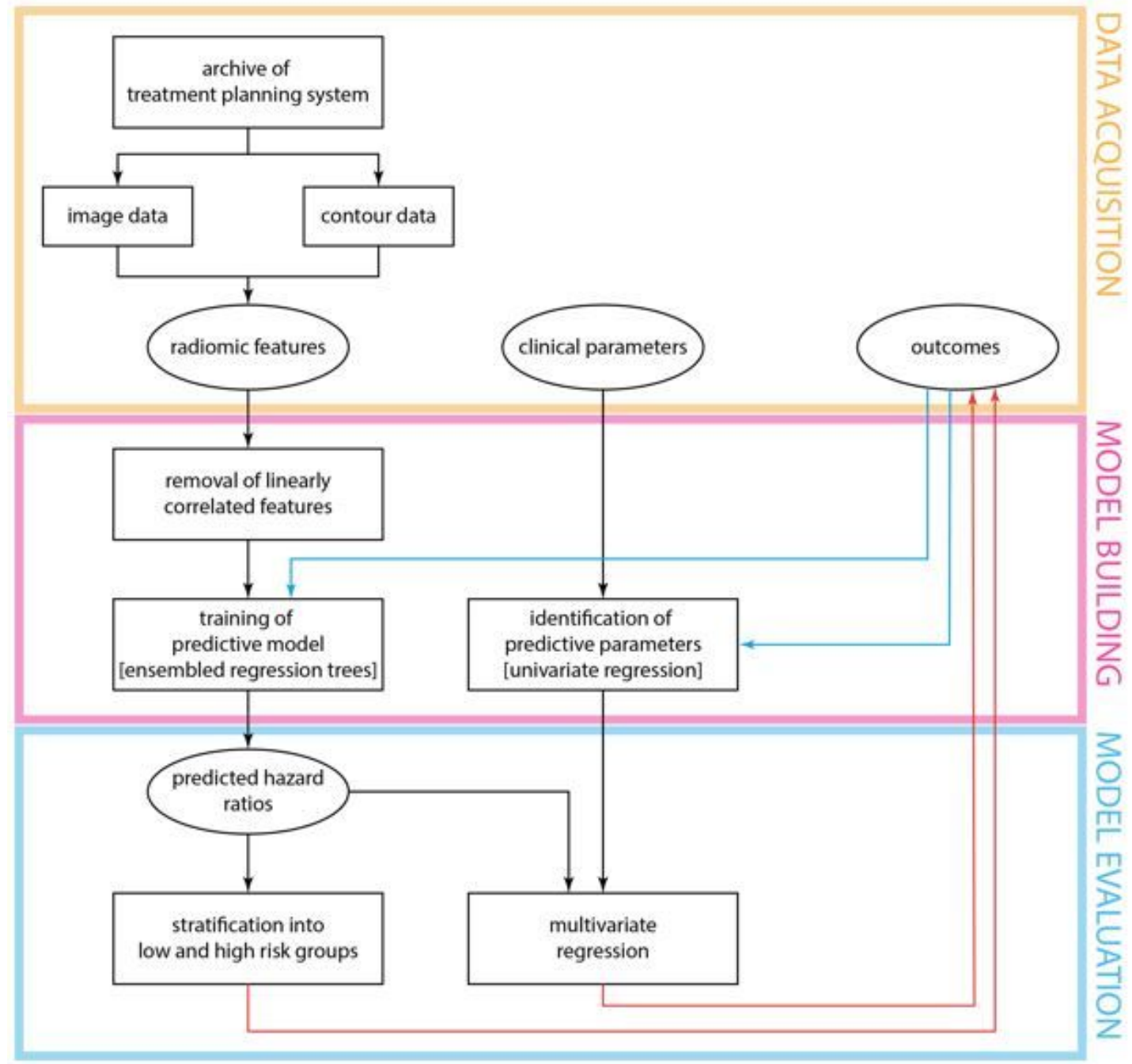

Figure 1

Workflow for generating and validating the developed models. 

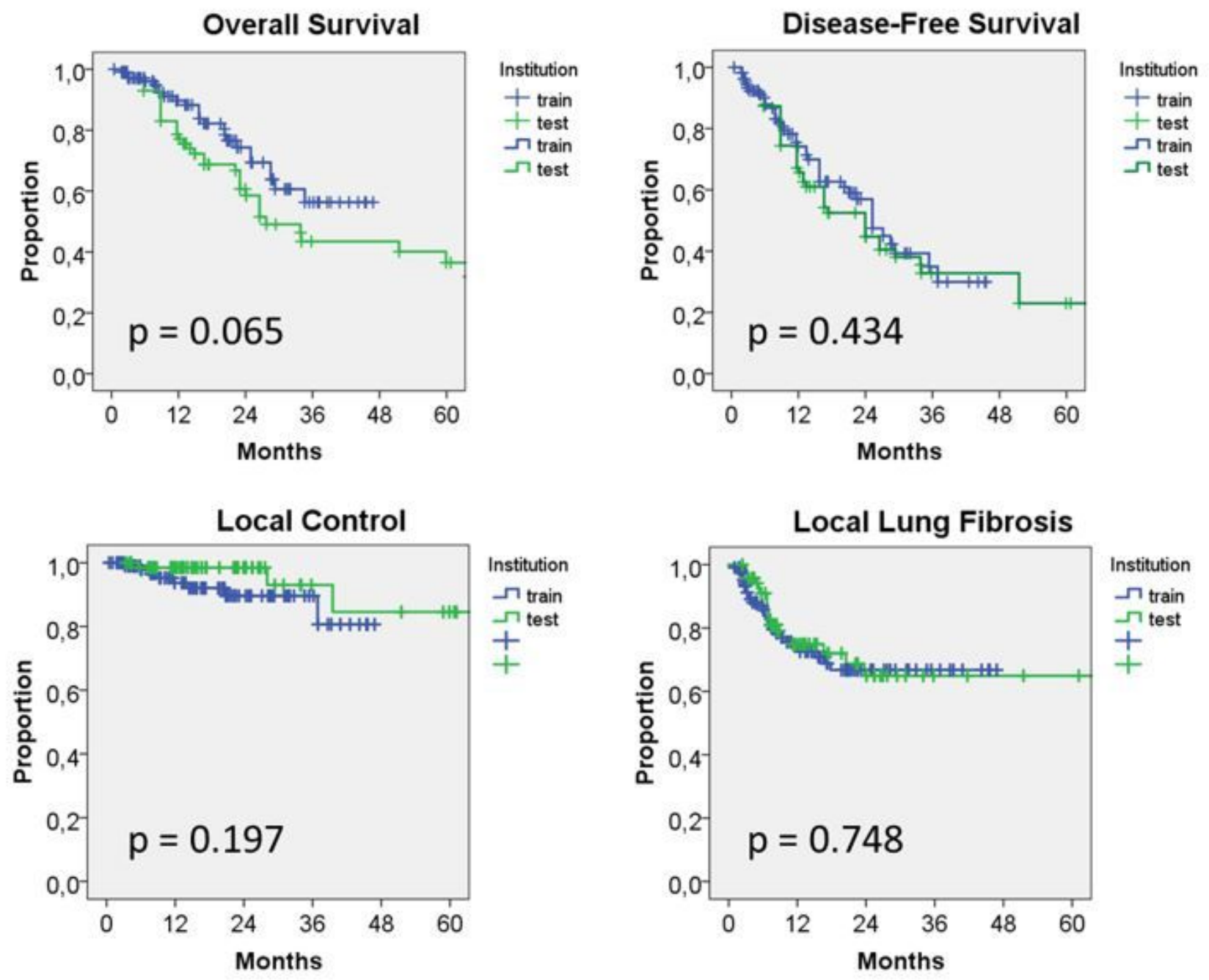

Figure 2

Survival curves for overall survival (OS), local control (LC), disease free survival (DFS) and occurrence of local lung fibrosis after SBRT for the training and testing cohort. No significant difference between the cohorts was measured for any endpoint. 

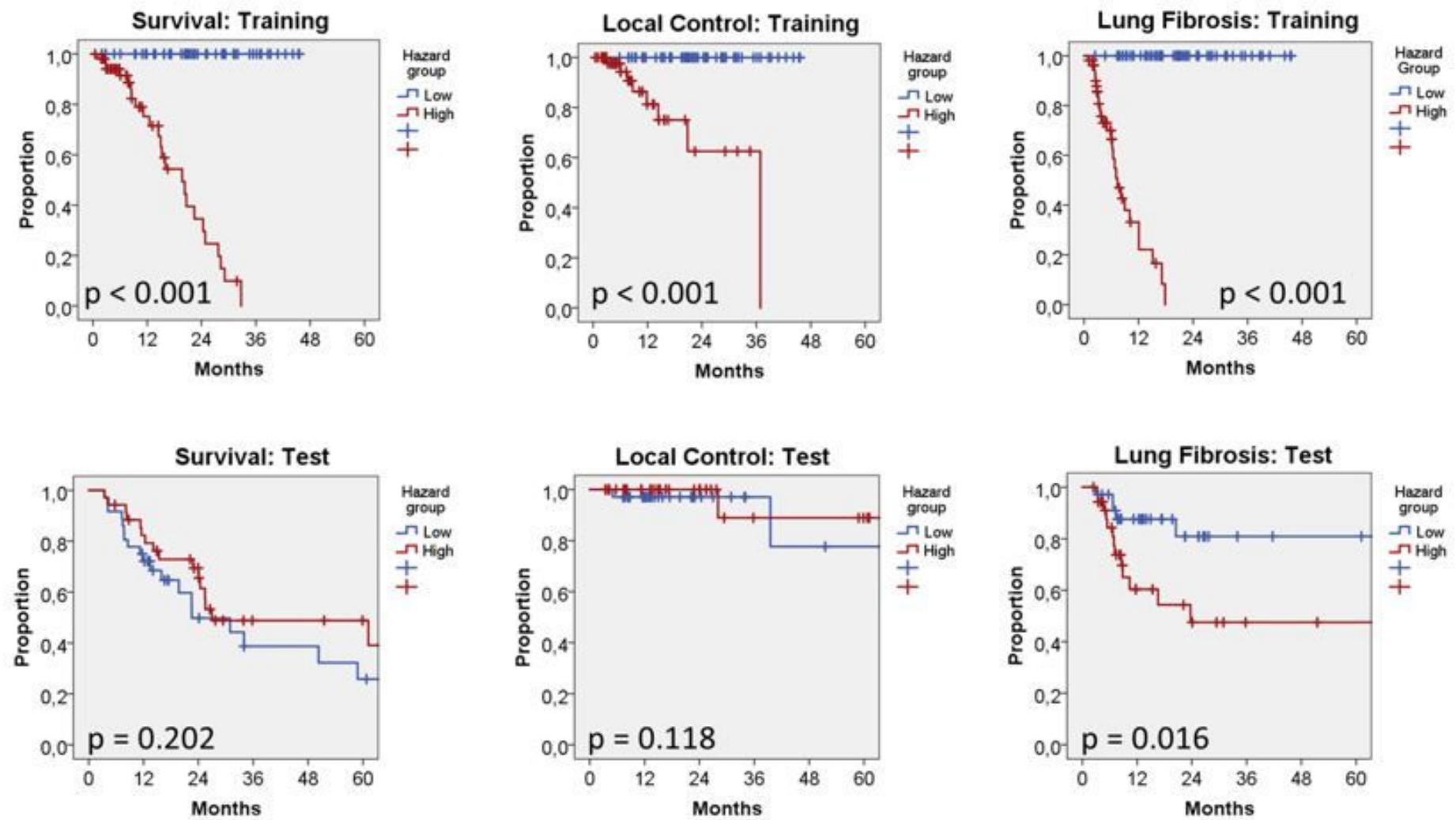

\section{Figure 3}

Kaplan-Meier curves displaying performance of the radiomics model in the training and test cohorts when stratifying patients into low and high risk groups 


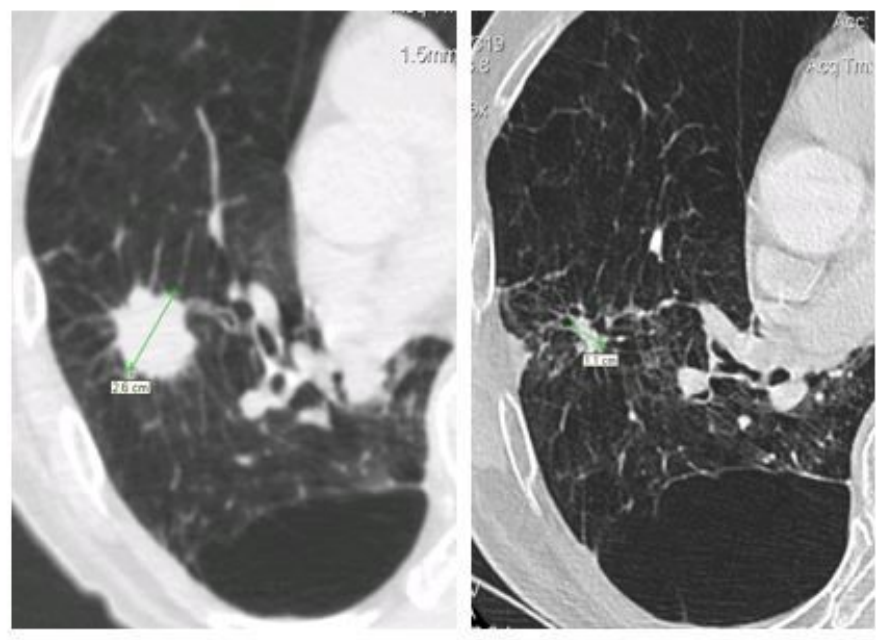

3x15Gy, F-up 9months

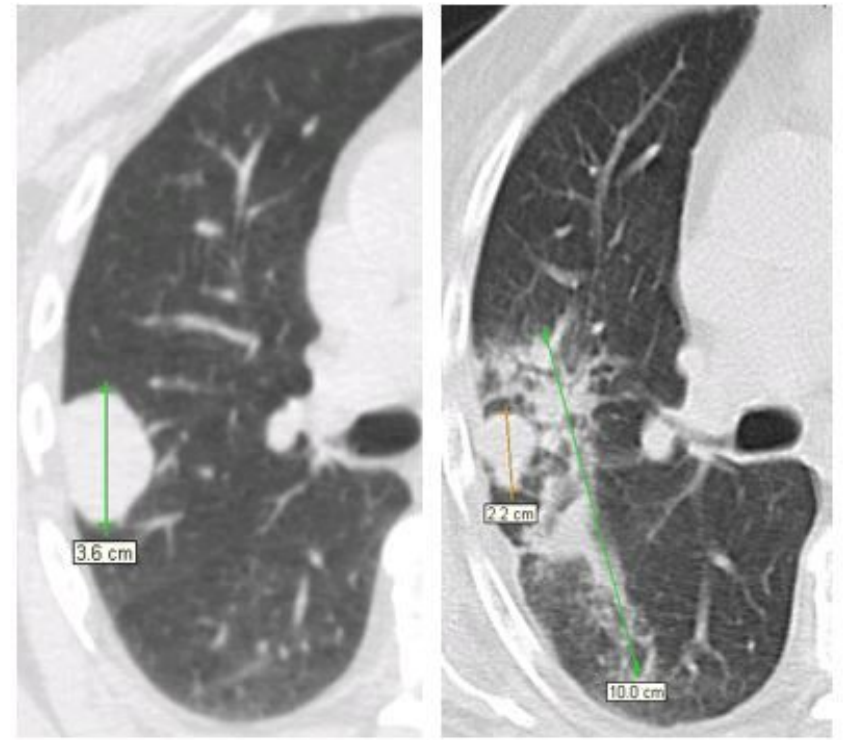

5x10Gy, F-up 7months
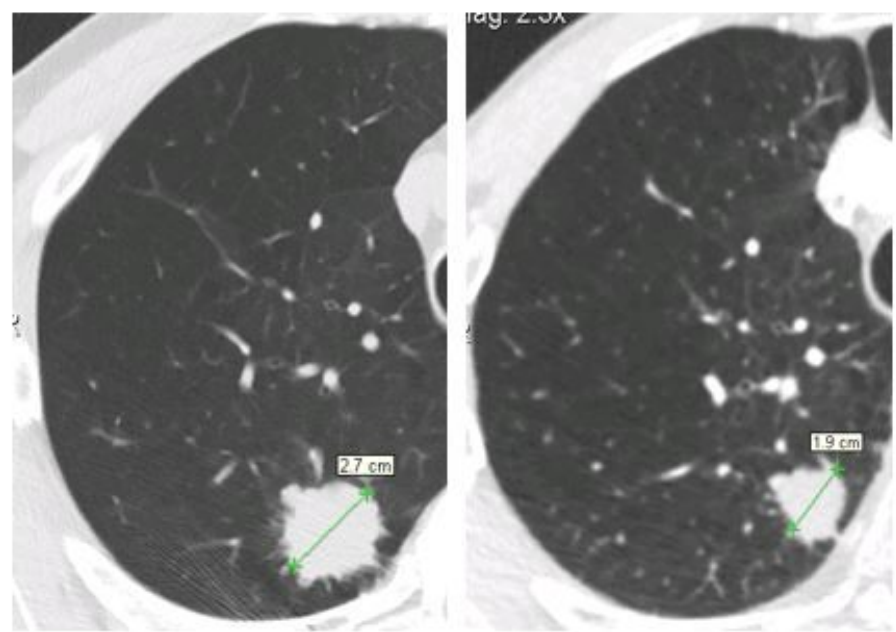

3x17Gy, F-up 12months
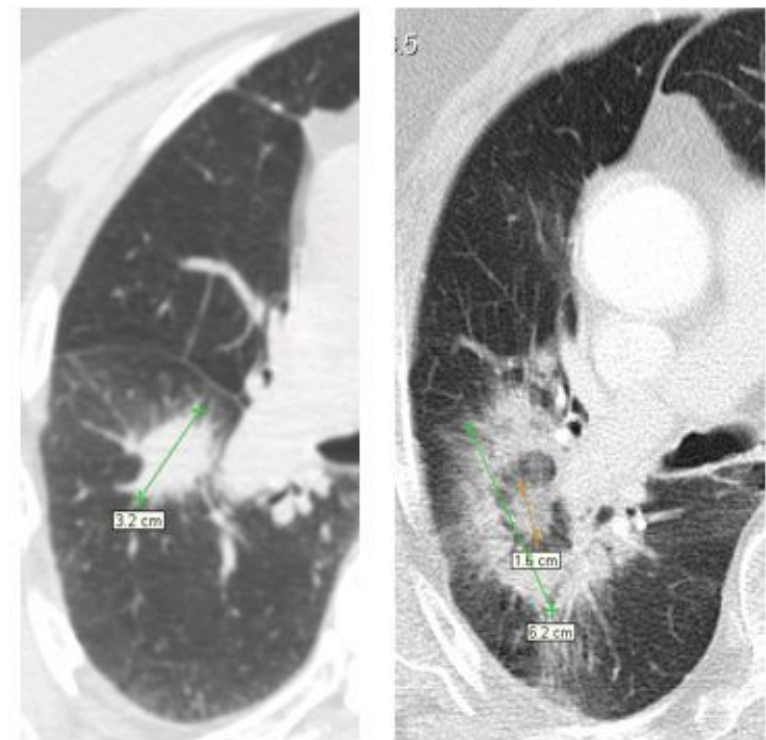

3x16Gy, F-up 3months

Figure 4

Representative chest CT images of patients who did not (upper row) or did (lower row) develop local lung injury induced by robotic stereotactic body radiation therapy of early-stage non-small cell lung cancer 